
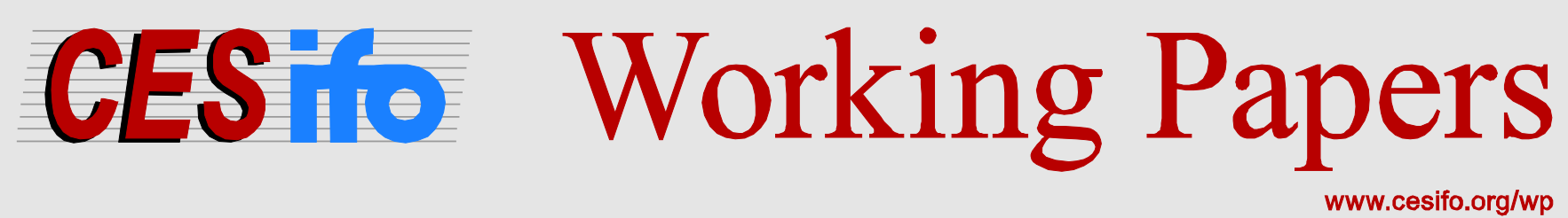

\title{
Fiscal Multipliers and the Choice of Zero Lower Bound Modeling
}

\author{
Thomas Siemsen \\ Sebastian Watzka
}

CESIFO WORKING PAPER NO. 4342

CATEgory 6: Fiscal Policy, Macroeconomics and GROWTH

JULY 2013

An electronic version of the paper may be downloaded

- from the SSRN website:

- from the RePEc website:

- from the CESifo website:

WWW.SSRN.com

www.RePEc.org

www.CESifo-group.org/wp

\section{CESifo}




\title{
Fiscal Multipliers and the Choice of Zero Lower Bound Modeling
}

\begin{abstract}
In this note we elaborate on the effect of the modeling choice of the zero lower bound on the size of the fiscal multiplier. To this end we contrast two different ways to implement the ZLB in a New Keynesian model: the ZLB modeled as an endogenous central bank reaction to a contractionary demand shock as in Christiano, Eichenbaum, Rebelo (2011) and the ZLB modeled as an exogenous monetary shock as in Cogan, Cwik, Taylor, Wieland (2010). We find that only the former treat the ZLB as an appropriate constraint for policy. We show that the economic significant differences in the size of the fiscal multiplier are not only due to differences in the timing assumption of government spending but also driven by the choice of the ZLB modeling. Ceteris paribus, the impact multiplier is higher if the ZLB is modeled appropriately as a constraint.
\end{abstract}

JEL-Code: E520, E620, E630.

Keywords: zero lower bound, fiscal multipliers, fiscal policy, monetary policy.

Thomas Siemsen

Seminar for Macroeconomics

University of Munich

Ludwigstrasse 28

80539 Munich

Germany

Thomas.Siemsen@econ.Imu.de
Sebastian Watzka

Seminar for Macroeconomics

University of Munich

Ludwigstrasse 28

80539 Munich

Germany

Sebastian.Watzka@econ.Imu.de 


\section{Introduction}

There has been a growing debate within the macroeconomics literature over the size of the fiscal multiplier. Special emphasis has recently been placed on the effects of the zero lower bound (ZLB). Two recently influential papers were Cogan, Cwik, Taylor, and Wieland (2010) (henceforth CCTW) and Christiano, Eichenbaum, and Rebelo (2011) (henceforth CER). These two papers reach very different conclusions as to the size of the fiscal multiplier, even though both analyze expansionary fiscal policy in similar models at times when the ZLB is binding. Whilst CER find multipliers that can be substantially larger than one when the ZLB is binding, CCTW instead find much smaller multipliers of typically only slightly above unity.

In this note we dig deeper into the question of how the ZLB is modeled in each of these two papers. By doing so we will show that the ZLB in CCTW is in fact modeled as expansionary monetary policy. The central bank deliberately sets its policy rate to zero even though the Taylor rule would instead indicate a positive nominal policy rate. Hence, in CCTW the "ZLB" is not really a bound or constraint on the central bank. CER instead model the ZLB as the endogenous central bank reaction to a contractionary aggregate demand shock. The nominal rate is stuck at the ZLB whilst the optimal Taylor-implied nominal rate is instead negative. Here, monetary policy is too tight at the ZLB.

CER and Eggertsson (2011) (see also Woodford, 2011) attribute part of the deviation of the fiscal multipliers to different assumptions on the timing of government spending. This difference would not necessarily cause a problem since the timing of government spending is, at least to some extend, within the discretion of policy makers. Our analysis shows, however, that it is also the difference in modeling the ZLB that leads to economic meaningful differences in the size of the fiscal multipliers.

This analysis is important first from a theoretical perspective to better understand the mechanics of government spending at the ZLB. Second, and possibly more important, our analysis is crucial for policy making. Whilst policy making in the US was largely influenced by the studies of Romer and Bernstein (2009) and backed by CER, policy making in Europe, and in particular in Germany, was largely influenced by the study of CCTW. By showing that the results of CCTW are driven by side effects of modeling the ZLB in their very special and rather counter-intuitive way, we hope to strengthen policy makers' confidence in timely stimulation of aggregate demand. 


\section{Model}

To switch off any effects other than the modeling of the ZLB onto the size of the fiscal multiplier we use a unifying framework onto which the ZLBs are imposed. The representative household $i \in[0,1]$ maximizes the present value of life-time utility subject to a nominal budget constraint.

$$
\begin{gathered}
\max _{\left\{C_{t}(i), N_{t}(i), B_{t}(i)\right\}_{t=0}^{+\infty}} \sum_{t=0}^{+\infty} \beta^{t}\left\{\frac{\left[C_{t}(i)-a C_{t-1}\right]^{1-\sigma}}{1-\sigma}-v \frac{N_{t}(i)^{1+\varphi}}{1+\varphi}\right\} \\
\text { s.t. } \\
P_{t} C_{t}(i)+B_{t}(i) \leq W_{t} N_{t}(i)+\left(1+i_{t}\right) B_{t-1}(i)-T_{t}(i)
\end{gathered}
$$

where $\beta$ is the household's discount factor, $P_{t}$ is the price level, $C_{t}(i)$ is consumption, $B_{t}(i)$ is savings, $W_{t}$ is the nominal wage rate, $N_{t}(i)$ hours worked, $i_{t}$ is the nominal interest rate and $T_{t}(i)$ are net transfers.

Heterogeneous firms $j \in[0,1]$ are owned by the households. Each firm produces quantity $Y_{t}(j)$ according to the production function $Y_{t}(j)=N_{t}(j) .{ }^{1}$ Firms are monopolistically competitive and face Rotemberg price adjustment cost.

$$
\begin{aligned}
\max _{\left\{N_{t}(j), P_{t}(j)\right\}_{t=0}^{+\infty}} \mathbb{E}_{0}\left[\sum _ { t = 0 } ^ { + \infty } \Lambda _ { 0 , t } \left\{P_{t}(j) Y_{t}(j)\right.\right. & \left.\left.-W_{t} N_{t}(j)-\frac{\vartheta}{2}\left(\frac{P_{t}(j)}{P_{t-1}(j)}-1\right)^{2} P_{t}\right\}\right] \\
\text { s.t. } & \\
Y_{t}(j) & =N_{t}(j) \\
Y_{t}(j) & =\left(\frac{P_{t}(j)}{P_{t}}\right)^{-\varepsilon} Y_{t}
\end{aligned}
$$

where $\Lambda_{0, t}$ is the pricing kernel and $\vartheta$ is the Rotemberg parameter. The model is closed with by the market clearing condition

$$
Y_{t}=C_{t}+G_{t}+\frac{\vartheta}{2}\left(\pi_{t}-1\right)^{2},
$$

the aggregate production function

$$
Y_{t}=N_{t}
$$

and the monetary policy function discussed below.

\footnotetext{
${ }^{1}$ We completely abstract from capital in our model. A model with capital will generally exhibit larger fiscal multipliers due to the effect of the real rate on investment. We repeated our exercises for a model with capital accumulation, receiving qualitatively robust results.
} 
Let $Z_{t}$ denote the Taylor rule implied "shadow interest rate"

$$
Z_{t} \equiv i+\phi_{\pi} \hat{\pi}_{t}+\phi_{Y} \hat{Y}_{t}
$$

with $i$ being the steady state nominal policy rate and $\hat{\pi}_{t}$ and $\hat{Y}_{t}$ denoting percentage deviation from steady state values of inflation and output, respectively. From here on we leave the unifying standard New Keynesian framework to contrast the aforementioned two avenues to implement the ZLB.

CER implement the ZLB as an endogenous central bank reaction to an aggregate demand shock, modeled as a jump in the discount factor $\beta$. The output and inflation reduction will be so severe that the Taylor rule implied shadow interest rate turns negative. The central bank is stuck at the ZLB and has no scope for further easing.

CCTW in contrast superimpose the ZLB onto the Taylor rule. The policy rate here is given by

$$
i_{t}=\Theta_{t} \cdot 0+\left(1-\Theta_{t}\right) \cdot Z_{t}
$$

To push the model onto the ZLB the deterministic shock process $\Theta_{t}$ is set equal to unity for a certain period in time. The presence of the ZLB is thus not an endogenous and systematic reaction of the central bank to economic conditions and not linked to the level of the shadow interest rate. The $\Theta$ shock has the exact same effects as an ordinary expansionary monetary policy shock. ${ }^{2}$

For our dynamic simulation we choose a standard quarterly calibration for our simulation exercise. ${ }^{3}$ We set $\beta=0.99, a=0.90, \sigma=1, \phi=1, \vartheta=46.6, \varepsilon=5, \phi_{\pi}=1.5, \phi_{Y}=$ $0.5, G / Y=0.2$ and $N=0.33$.

\section{Results}

In our first exercise we still abstract from government spending and study the specific mechanisms through which the ZLB is implemented in the two approaches. To provide the basic intuition for the operation mode of the ZLB we assume that the ZLB is binding for four quarters. Figure 1 shows the dynamics during end after the ZLB regime in the two different setups.

Clearly the two ZLB-push shocks convey a completely different intuition. The ZLB acts indeed expansionary in the CCTW setup, as one would expect after an expansionary monetary policy shock. Both output and consumption increase. This leads to inflationary expectations and with the nominal rate fixed at zero to a initial reduction of the real rate

\footnotetext{
${ }^{2}$ For a complete description of the modeling approaches refer to the original papers.

${ }^{3}$ For further information on the solution algorithm see CER and Christiano (2010).
} 
of interest blow zero. Moreover, this exogenous shock should usher a systematic contractionary central bank response which drives the counterfactual Taylor rule implied shadow rate above its steady state value. Therefore, monetary policy is too loose at the ZLB which makes the label "ZLB" misleading as the nominal policy rate is unconstrained from above.

In contrast, the endogenously binding ZLB in CER is strongly contractionary. It induces a vicious deflationary spiral since a reduction in inflation raises the real rate quid pro quo which further depresses output. Monetary policy is too tight with the policy rate being above the shadow interest rate.

Figure 1: Effect of the ZLB-push shock
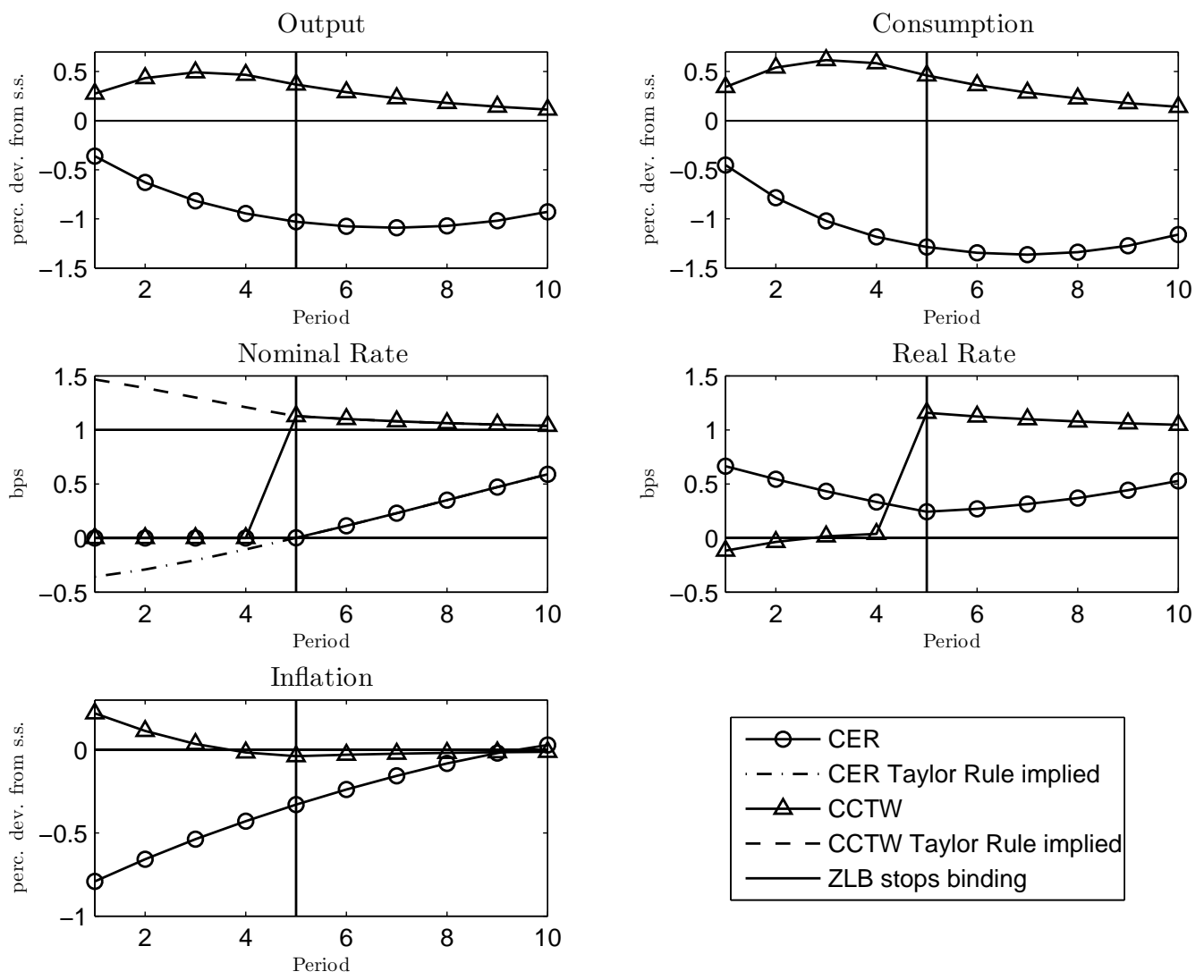

$$
\begin{aligned}
& \hline \_ \text {CER } \\
& -- \text { CER Taylor Rule implied } \\
& \triangle \_ \text {CCTW } \\
& --- \text { CCTW Taylor Rule implied } \\
& \text { Z ZLB stops binding }
\end{aligned}
$$

To analyze whether these two different ZLB-push shocks do indeed affect the size of the fiscal multiplier we implement the very same government spending path for both ZLB setups. We assume that government spending is increased by one percent over the whole ZLB regime which we assume to be binding for 12 quarters. If indeed the different sizes of the fiscal multiplier are only driven by the timing of the government spending path, we would expect not to observe any deviations in the multipliers in this exercise. However, it turns out that significant differences still arise. 
Bearing in mind that our model is too simplistic to ascribe a strong meaning to the exact size of the multiplier Figure 2 shows that the multipliers do not only differ quantitatively but also qualitatively. While in the CER setup the multiplier is on impact above unity and increases for the first four quarters the multiplier is initially below unity under the CCTW ZLB-push shock and decreases monotonically over the whole simulation horizon.

Figure 2: Fiscal Multipliers

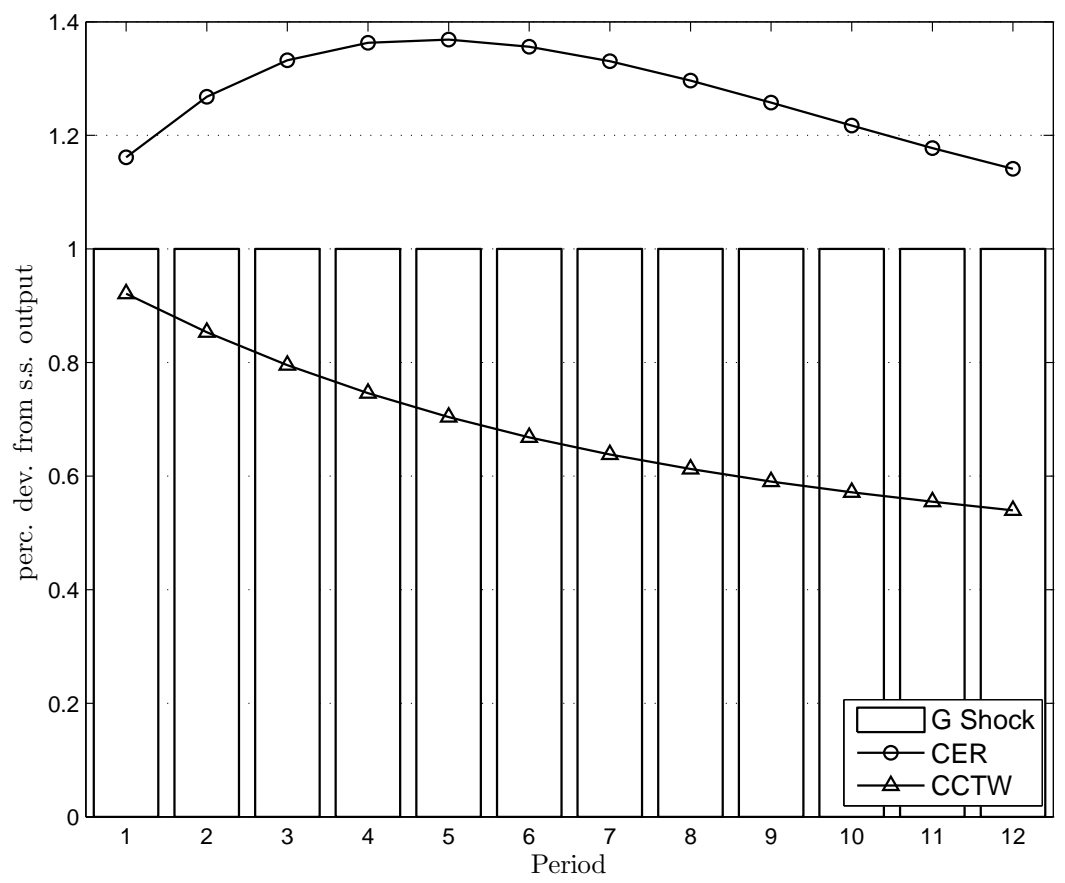

To provide an intuition why the fiscal multiplier is systematically lower in CCTW we offer the following intuitive take: following CER one can show that the government spending multiplier is up to first order given by

$$
\begin{aligned}
\frac{d\left(\hat{Y}_{t}^{G}-\hat{Y}_{t}^{\neg G}\right)}{d G_{t}}=\frac{d G_{t}}{\bar{Y}}+\frac{\bar{C}}{\sigma \bar{Y}} \cdot\{ & \left\{\sum_{k=0}^{\bar{T}} \frac{\partial\left[\hat{\pi}_{t+k+1}^{G}-\hat{\pi}_{t+k+1}^{\neg G}\right]}{\partial G_{t}}+\right. \\
& \left.\sum_{k=1}^{T}\left(\frac{\partial\left[\hat{\pi}_{\bar{T}+k+1}^{G}-\hat{\pi}_{\bar{T}+k+1}^{\neg G}\right]}{\partial G_{t}}-\beta \frac{\partial\left[d i_{\bar{T}+k}^{G}-d i_{\bar{T}+k}^{\neg G}\right]}{\partial G_{t}}\right)\right\} \cdot d G_{t}
\end{aligned}
$$

where superscript $G$ variables denote percentage deviations from steady state under both a ZLB-push and a government spending shock and superscript $\neg G$ variables denote percentage deviations from steady state only in response to a ZLB-push shock. $\bar{T}$ denotes the period the ZLB ceases to bind and $T$ the simulation horizon. 
The first sum on the right hand side captures the output impact during the ZLB regime. Since $i_{t}$ is constant at zero, the real rate of interest and hence the effect on output is solely determined by inflation. The stronger the increase of inflation (decrease of deflation) due to government spending, the lower is the real rate and hence the higher is the impact multiplier. The second sum captures the output impact after the ZLB ceases to bind. Again, the multiplier is higher the stronger the inflationary pressure of the government spending increase. But now the nominal rate of interest is no longer constant. The real rate of interest is also determined by the nominal rate of interest. The stronger $i_{t}$ increases due to government spending once the liquidity trap is left, the lower the impact multiplier.

This formula helps to provide the basic intuition why the multiplier is systematically lower in the CCTW ZLB-world. Consider the ZLB regime first. During this period the effect of government spending on inflation is stronger in the CER setup than in the CCTW setup. Following a similar argument as in Eggertsson (2011) the AS curve is steeper the stronger the persistence of inflationary expectations. Since in CCTW the effect of the ZLB can be easily offset by the central bank once the liquidity trap is over as monetary policy has to tighten and the policy rate is unconstrained from above, inflationary expectations during the ZLB will be bounded. Whereas in CER the damage done during the ZLB can not quickly be repaired afterwards. This would require a strong monetary expansion but at the vicinity of the ZLB the policy rate is still contained from below. Therefore, output and inflation will remained depressed even after the ZLB stops binding (see also Figure 1 ) and hence deflationary expectations will be strong. This induces a steeper AS curve in CER compared to CCTW. In the tipsy-turvy world with an upward sloping AD curve a steeper AS curve will lead to a stronger increase output given a shift in the AD curve. This leads to a stronger effect in CER as government spending breaks the vicious deflationary spiral. Therefore, the first term on the right hand side is larger in CER.

Consider now the period after the ZLB. Once the economy is out of the liquidity trap government spending exhibits similar inflation dynamics in both setups. Therefore, the second term on the right hand side is about the same in the two setups.

In CCTW the expansionary ZLB-push shock drives the shadow interest rate above steady state. Therefore, the central bank will tighten monetary policy strongly once the ZLB is over to offset the inflationary pressure built up during the liquidity trap and to return to the shadow interest rate. In the CER setup monetary policy will still be loose once the ZLB is over since the economy is still depressed and only gradually recovering (see also panel 4 in Figure 1 ). Therefore, the transition will be rather smooth in CER and the last term on the right hand side is larger (less negative). ${ }^{4}$

Thus, to sum up, the fact that the ZLB is expansionary in CCTW induces both attenu-

\footnotetext{
${ }^{4}$ The simulation results are available from the authors upon request.
} 
ated inflation dynamics at the ZLB and stronger policy rate dynamics after the ZLB than in CER. For these reasons the fiscal multiplier is systematically lower in CCTW given the same timing in government spending.

\section{Conclusion}

We showed that the substantial differences in fiscal multipliers measured on the one side by CER and others and by CCTW on the other side are not only due to different timing assumptions of government spending. They are also strongly influenced by the way the ZLB is modeled. The fact that CCTW implement the ZLB via an expansionary monetary policy shock in an otherwise standard New Keynesian model leads to lower multipliers compared to a contractionary preference ZLB-push shock given the same path of government spending. This results is important to put the policy conclusions drawn from these studies into the right context. If fiscal policy is seriously taking into account the ZLB our results show that it should rely more on the results of CER.

\section{References}

Christiano, L. (2010): “Technical Notes for Discussion of Eggertsson, What Fiscal Policy is Effective at Zero Interest Rates," mimeo.

Christiano, L., M. Eichenbaum, and S. Rebelo (2011): "When Is The Government Multiplier Large?," Journal of Political Economy, 119(1), 78-121.

Cogan, J., T. CwiK, J. Taylor, and V. Wieland (2010): “New Keynesian versus old Keynesian government spending multipliers," Journal of Economic Dynamics E Control, 34, 281-295.

Eggertsson, G. (2011): "What Fiscal Policy is Effective at Zero Interest Rates," NBER Macroeconomics Annual 2010, 25(1), 59-112.

Romer, C., and J. Bernstein (2009): "The Job impact of the American Recovery and Reinvestment Plan,".

Woodford, M. (2011): "Simple Analytics of the Government Expenditure Multiplier," American Economic Journal: Macroeconomics, (3), 1-35. 